\title{
Adam Smith and cultural relativism
}

\author{
SAMUEL FLEISCHACKER \\ University of Illinois, Chicago
}

\begin{abstract}
This paper explores the presence of both relativistic and universalistic elements in Adam Smith's moral philosophy. It argues that Smith is more sympathetic to the concerns of anthropologists than most philosophers have been, but still tries to uphold the possibility of moral judgments that transcend cultural contexts. It also argues that the tensions between these aspects of his thought are not easy to resolve, but that Smith's sensitivity to the issues that give rise to them makes him a useful figure with whom to think through the relationship between anthropology and moral philosophy to this day.
\end{abstract}

Keywords: Adam Smith, culture, relativism, anthropology, moral judgment

JEL Classification: A11, B12, B31, B40

I would like in this paper to explore the degree to which Adam Smith's moral philosophy can fairly be understood as relativistic, mostly for the purpose of stimulating wider scholarly attention to the question. I shall not do much to resolve it here, although I will point a little in that direction, and I hope as well to indicate that the fact that Smith's philosophy so much as raises this question has a number of interesting implications for how we understand him.

One implication that I would like to stress is that the hint of relativism in Smith has advantages, and not just disadvantages, for the use of his work today in moral theory. Smith has the unusual merit of providing a view of morality that anthropologists, and not just philosophers, can respect. Generally, philosophers and anthropologists find themselves at loggerheads over morality, to the extent that it can be doubtful whether they are even discussing the same concept. The reasons for this conflict go to the heart of the two disciplines. When an anthropologist sets out to discover what morality is, she usually tries to

AUTHOR's Note: A previous version of this paper was published in German as "Smith und die Kulturrelativismus" in the volume Adam Smith als moralphilosoph, edited by Christel Fricke and Hans-Peter Schuett (2005). 
preserve a distance from the question, "what norms ought to count as moral ones?" since answering that question might skew her ability to approach her subject matter objectively. ${ }^{1}$ Instead, she proceeds by asking the people in the culture she studies what behavior they in fact approve and disapprove. When a philosopher tries to determine what morality is, one of the main things he or she is looking for is a standard by which to judge-to evaluate-what people in any given culture approve and disapprove. The anthropologist and the philosopher thus set out on a collision course with one another, and wind up, unsurprisingly, with very different conceptions of what morality is. Given her methodology, the anthropologist tends to identify moral norms with those norms a society treats with a strong sense of "piety", which it regards as "sacred" in some sense-more or less with what was called "taboo" in Hawaii. ${ }^{2}$ For the philosopher, by contrast, "taboo" and the emotional reactions to it give precisely the wrong sort of content to the word "morality". But the consequence of this approach to the subject is that philosophers often wind up writing out most or all of a society's purportedly moral norms as irrelevant, at best, to morality, while anthropologists often find that what philosophers consider to be morality would be unrecognizable by the cultures they study.

At the heart of this debate lies a question about the need for moral norms to be rationally justified. Modern moral philosophy, from Hobbes onwards, has aimed to give reasons for behavioral norms independent of religious commitments, or at least of any non-rational, purely faithbased religious commitment. Consequently, philosophers tend to write norms off as non-moral if they are preserved solely by way of a societal horror at their violation, or delight in their observance. Sometimes morality has been defined in terms of universality-moral norms are all and only those norms that all human beings can endorse; sometimes it has been defined directly in terms of rationality-moral norms are all and only rational norms (and universal then, because they are rational). But in any case it is supposed to be part of the definition of morality

\footnotetext{
1 "The scientific study of generalized social forms requires $[. .$.$] that the investigator$ free himself from all valuations based on our culture. An objective, strictly scientific inquiry can be made only if we succeed in entering into each culture on its own basis, if we elaborate the ideals of each people and include in our general objective study cultural values as found among different branches of mankind" (Boas 1932, 204-205).

${ }^{2}$ See Alasdair MacIntyre's After virtue (1984, 111-112). Anthropologists often appeal approvingly to the notion William Sumner called "mores", the violation of which, in each society, elicits a strong, but nonjuridical, negative reaction. See, for instance, A. L. Kroeber's Anthropology (1948, § 116, 265-267).
} 
that anything felt to be right or wrong merely by one group of human beings among others, and which others cannot be persuaded to regard in the same light, will not be morally right or wrong-will be mere "taboo". An advantage of developing a properly philosophical understanding of morality is indeed supposed to be that one can thereby sift out moral norms from taboos, and, in that light, criticize standards for behavior in various societies. This is no small advantage, I hasten to say: being able to reject taboos encouraging prejudice against blacks, Jews, women, homosexuals, and so on, has been an important moral achievement, and it would not have been possible if morality had to be identified with taboo.

Yet there is something unsatisfying about the philosopher's approach to morality. The philosopher needs to write off as inappropriate a large chunk of what most people, in most places, consider to be moral and immoral. And the philosopher sees this large part of what is ordinarily labeled "morality" not just as incorrectly so labeled, but as obviously irrelevant to morality. When Eskimos suppose there is something intrinsically wrong with eating caribou and seal at the same meal, the philosopher says they are making an obvious mistake, especially if they suppose this to be a wrong of the same kind or order as an injury to other persons. When religious Christians say there is something intrinsically wrong with consensual homosexual sex, philosophers are inclined to see this as a similarly obvious mistake. This makes it look as if ordinary people do not understand what morality is-ordinary people in other cultures, especially, tend to appear as if they are completely confused about morality-which is both offensive and implausible. It also means the philosopher's definition of morality is unhelpful for descriptive studies of how people actually use moral language, or of moral development-of how individuals in societies come to think of themselves as having a moral point-of-view. Cutting the socialized taboo away from moral norms makes it hard to explain how those norms can get learned.

In addition, the philosopher's picture cuts morality off too much from other values, separates it too sharply from aesthetics and decorum, to say nothing of religion and metaphysics. Taboos about what foods to eat often function in practice just like taboos against injury or unkindness. The explanation cultures tend to give for all their important norms is that those norms reflect a cosmic order; a violation of any of these norms is wrong, then, because it disturbs or defiles a 
natural and beautiful cosmic pattern. By calling this a mistake, and insisting that morality concerns only what human beings owe to each other, the philosopher cuts morality off from the possibility that it might give the whole of our lives, not just our interpersonal relations, an intrinsic meaning; that it might help define all our goals and concerns.

Finally, the philosopher's emphasis on the rationality of moral norms has certain difficulties even for prescriptive purposes. Norms that we endorse rationally may not be ones that we particularly care about observing, and norms that we care about observing are very often, like the Hindu ones about eating beef, not norms for which we have any good argument. For the philosopher's moral recommendations-say, about treating black and white people equally - to get a grip on us, they need to be built into our emotional reactions. We need to develop a taboo against discriminating on the basis of race.

Now Smith, unlike practically all of his predecessors, takes very seriously the taboo-quality, the aura of "sacredness" that surrounds moral norms, ${ }^{3}$ and defines "morality" in a way that hews closely to the use of that word in ordinary life. Not only does his procedure for moral judgment, as we shall see more in a moment, make the standards of

\footnotetext{
${ }^{3}$ Consider the difference between Hume and Smith, in this regard. For Hume, "sacred" simply means "inviolable" (see "An enquiry concerning the principles of morals", 200-201); to call a rule "sacred" is just to say that it brooks of no exceptions (see A treatise of human nature, 501, 531-532). But to say that a rule should never be violated is not yet to say that it deserves awe, respect, or any of the other psychological phenomena normally associated with "sacredness", in its ordinary usage. The laws of nature, like Newton's law of gravity, are inviolable, but we hardly feel they are sacred. Hume explicitly compares the apparent superstitions that surround the claiming of property with the real superstitions that, he believes, surround religious rituals, making clear that he has no use for the rules of justice to be associated with awe or with any sort of taboo (see A treatise of human nature, 197-200): the laws of justice are and should be, as much as possible, a rational business, not something shrouded in mysterious feelings. For Smith, by contrast, we lay down inviolable moral rules to ourselves in order to counteract the "misrepresentations [...] concerning what is fit and proper to be done" to which we may be led by "furious resentment" or passionate excesses of self-love. The rules then work precisely by way of the "awe and respect" they engender, by the fact that they mark out a region of action as if it were forbidden to us by a higher power, mark it as taboo, as something we should not even contemplate entering (see TMS, 160-161). Thus when Smith calls his rules of justice "sacred" (as in TMS, 138, 161, 330), his usage fits in with the ordinary meaning of that word; the awe-inspiring quality of the rules, not their mere inviolability, is central to their functioning. (Nor does the fact that we come up with the rules ourselves, that we "lay them down to ourselves", do anything to vitiate the possibility of regarding them as God's laws: if our moral sentiments are God's "viceregents within us", it is perfectly reasonable to regard the rules to which they lead us as simply one way by which God's power manifests itself.)
} 
one's society largely determinative of one's moral judgments, but his very decision to identify moral judgment with the judgment of the impartial spectator seems underwritten by a belief that this is what most people mean by "moral judgment" in ordinary life. It is characteristic of Smith's method in all his work to try to draw philosophical definitions out of commonsensical ones, and in The theory of moral sentiments (TMS henceforth) he appeals over and over, as evidence for his points, to what "we think", "we admire", "we approve" (e.g., TMS, 17, 24, 62, 178, 323). In one important instance, he does so to establish that "we" do not agree with Hutcheson that morality can be identified with benevolence (TMS, 304). His arguments for why morality cannot be equated with prudence, or with social utility, are also, I think, best understood as resting on the claim that, in ordinary life, we simply do not use the word "moral" to designate what serves either an agent's self-interest or the utility of a society; moral language is not identical with prudential or utilitarian language. Rather, when we say an action is morally right what we mean is precisely that it wins the approval of an impartial spectator: "The very words, right, wrong, fit, improper, graceful, unbecoming mean only what pleases or displeases [our moral] faculties" (TMS, 165).

Smith thereby identifies moral thinking with what most people, in everyday life, already regard as moral thinking, rather than looking, as Hobbes and Bentham do, for some external purpose that such everyday talk serves, or, as Cudworth and Clarke do, and as Kant would do later on, for a rational structure underlying the everyday talk. ${ }^{4}$ On these, more standard approaches to morality, everyday moral talk may be thoroughly confused, and may need to be thoroughly overhauled in the name of its fundamental purpose or structure. On Smith's approach, societies may well make moral errors here and there, but it is impossible that they get the entire nature and purpose of moral thinking wrong. For Smith, morality just is the social practice by which people correct one another for not adequately living up to their society's standards of

\footnotetext{
${ }^{4}$ There clearly are a number of very important social purposes that moral practices may serve (individual happiness, social peace and stability, and the like, which Smith takes note of at TMS, 20, 45, 86, 149-150). But serving those purposes is not part of the definition of morality, and it is not necessarily a part of those practices that we advert, directly or even indirectly, to those purposes when we correct ourselves and our neighbours. The purpose of morality lies beyond the frame, as it were, beyond the picture of what morality actually is. This nonteleological attitude in fact does belong to the phenomenology of moral judging, and it is in holding off the question of teleology that Smith improves on Hobbes, Hutcheson, and Hume, and is rightly regarded as kin to Kant.
} 
conduct (in particular, for not doing so out of excessive passion on behalf of their selfish interests); this definition is neutral as to what the society's standards of conduct might be, and according to it, the thought that societies might entirely misunderstand the nature of morality is quite literally unintelligible. ${ }^{5}$ It is in this sense that Smith may be regarded as the most anthropologically sensitive of modern moral philosophers-certainly, of moral philosophers in the 17th and 18 th centuries.

But it is precisely this anthropological sensitivity that opens Smith to the charge that his moral philosophy is beset by the relativism with which philosophers generally charge anthropologists. I do not know that Smith has a good answer to these charges, but the problem he faces is our problem too. In ordinary usage, a moral norm is usually conceived both as a proper guide to conduct and as something that in fact guides most people's conduct in some society. Hence the philosophical and the anthropological approaches to morality need to be reconciled, and the continuing division between these approaches reflects a deep difficulty in defining what morality is supposed to do. We gloss over that difficulty all too easily, at this point in the division of labor, by parceling these two aspects of morality out to two different kinds of professional. So even if Smith has no good answer to the question of how we bring the universalist and the culturally-relative aspects of morality together, the mere fact that his work brings out that question makes it worth thinking with him about it. In this paper I try to do that by exploring both the relativistic and the universalistic tendencies in Smith's moral thought. ${ }^{6}$ The discussion is divided into three parts: I consider first the evidence for reading Smith as some sort of relativist, then the evidence against that reading, and conclude with two sets of reflections on the difficulties in reconciling these two aspects of Smith.

\footnotetext{
${ }^{5}$ In TMS, 313-314, Smith says almost exactly this. See also the Wealth of nations (WN), 768-769.

${ }^{6}$ I am aware that the proper antonym of "relativist" is "absolutist" and the proper antonym of "universalist" is something like "tribalist" or perhaps "pluralist". The first pair of terms is a meta-ethical one, while the second is an ethical one. Nevertheless, absolutism about the foundations of ethics generally goes together with a strong ethical universalism, while relativism about ethical foundations goes almost without exception together with a strong endorsement of pluralism. For this reason, and because Smith is really torn between a meta-ethical threat of relativism and an ethical inclination towards universalism, I will refer to the tension I am drawing out of Smith mostly as one between "relativism" and "universalism".
} 


\section{SMITH'S RELATIVISM}

Adam Smith is one of the most respectful of 18th century writers towards other societies. Far from endorsing Hume's notorious speculation that only white civilizations have ever produced anything worthwhile, he lauds the magnanimity of Native Americans and Africans, describing the latter as far superior in character to the Europeans who enslaved them. ${ }^{7}$ Moreover, the passage about Africans comes from an entire division of TMS (Book V) devoted to the influence of culture on morals, in which Smith argues that "The different situations of different ages and countries are apt [...] to give different characters to the generality of those who live in them" (TMS, 204). He points to different standards of politeness in Russia and France, and a different balance of the gentle and the awful virtues in civilized and barbarian nations, describing these as "wide" and "essential" differences in the morals of different peoples (TMS, 208). ${ }^{8}$ Since the notion that morality might vary in accordance with culture was not widely accepted in Smith's time, ${ }^{9}$ moreover, the mere fact that he devotes a major division of his book to the subject is remarkable.

Still, the concession Smith makes to the role of culture here is a moderate one, which need not raise any specter of relativism. He condemns infanticide as a perversion of morality, even though it has been approved by whole cultures, and says that "the general style and character of conduct" can never be perverted in such a way, else the society in question would self-destruct (TMS, 211; see also 209). Cultural variation in morals is possible only within fairly narrow bounds; it never amounts to more than a matter of emphasizing one virtue over another, of what we might call the "shading" in our picture of how human beings should live: "the manners of different nations require different degrees

\footnotetext{
7 See Hume's "Of national characters" (Political essays, 86n); and Smith's TMS, 205, 206-207. There are echoes of Montaigne, and anticipations of Herder, in these passages, but such respect for non-Western societies is rare in the seventeenth and eighteenth centuries.

8 Jim Otteson, whose discussion of these matters I otherwise largely agree with, somewhat understates the importance Smith gives to cultural variation (Otteson 2002, 215-220). He quotes a passage on the page after the one I have just quoted to show that cultural differences in morality are "of small moment only" (TMS, 209; quoted at the top of Otteson 2002, 219). But Smith actually says there just that differences in morals due to "different professions and states of life" are of "small moment"; he gives rather greater significance to differences due to culture.

${ }^{9}$ The very term "culture", in its modern anthropological sense, was not to be invented until the nineteenth century. It was coined in 1843 by Gustav Klemm, as a new meaning for the German term "Kultur", and introduced into English by Edward Tylor in 1871. See Fleischacker 1994, chapter 5.
} 
of the same quality, in the character which they think worthy of esteem" (TMS, 209). On the evidence of Book V alone, we might say that Smith is a cultural pluralist, but not a relativist. He makes room for cultural variation within his picture of the good human life, but that picture, with its room for cultural variation, is supposed to hold for all human beings everywhere.

But in Books I and III of TMS a real relativism threatens the core of his thought. This can be brought out in several ways. First, to the extent that Smith's methodology works by way of appeal to what "we think", "we approve", and so forth, it is open to the objection that what the "we" in one community believes and feels may be very different from what the "we" in another community believes or feels. The appeal to common sense is connected to much that is attractive in Smith: to his avoidance of metaphysics in moral theory, ${ }^{10}$ and his resistance to utilitarianism. (There are utilitarian moments in Smith-at TMS, 90-91, and 326, for instance-but on the whole he denies that the judgments of the impartial spectator can be either reduced to or trumped by appeals to utility.) Still, the common-sense methodology that in some ways is so attractive opens Smith to the threat that common-sense philosophy characteristically faces: that common sense is relative to communities; ${ }^{11}$ that what is common sense in one culture may be utterly counterintuitive in another. This is particularly so, and these differences are particularly hard to overcome, in matters of morals. We may be able to correct common superstitions, in our own or another culture, by way of scientific data; we will not often change common moral beliefs that way.

Second, as Allan Gibbard (1990, 280) has pointed out, the fact that Smith sets up his account of moral approval as an outgrowth of each person's search for harmony with the feelings of the people around him or her (TMS, 16-17, 110-112) puts pressure on the account to make approval relative to communities. For if the impetus for seeking moral approval from others, and expressing approval and disapproval of those others, is that we want "to be beloved" (TMS, 41) and want our friends and neighbors to be lovable, that we want to share feelings with the others around us, then the goal we are aiming at will necessarily vary with variations in the types of feeling common among different groups

\footnotetext{
${ }^{10}$ It is an important theme of Charles Griswold's (1999) Adam Smith and the virtues of enlightenment that Smith abjures metaphysical appeals in his philosophy. For Griswold, that makes Smith something of a sceptic; I see him as a common sense philosopher instead. See further discussion in Fleischacker 2003, Part I, chapter 2.

${ }^{11}$ See Clifford Geertz's (1983) “Common sense as a cultural system”.
} 
of people. If the people around me are warmly effusive while the people around you are colder or more reserved, then you and I will seek to be different kinds of people, and will approve and disapprove of different kinds of actions and reactions in others. If moral approval aims to bring people in a community into a sort of emotional equilibrium with one another, then it will vary with the different strengths and types of emotion going into such an equilibrium in different places and times.

Third, and most deeply, the impartial spectator is constructed out of modes of judgment that seem essentially relative to a particular culture. We observe what our friends and neighbors say about how people should behave and we try to win their approval (TMS, I. i-iii). Then we find that some of their judgments are unfair-infected by interest (TMS, 129) or ill-informed (TMS, 114-115, 130-131)-and "in order to defend ourselves from such partial judgments, we [...] learn to set up in our own minds a judge between ourselves and those we live with" (TMS, 129; see also 135). But this impartial judge within us cannot defend us against the outsiders' judgments unless it uses the same standards of judgment that they do; it cannot otherwise engage with their judgments. Our society provides us with the "mirror" by which we can see our own conduct-"the countenance and behavior of those [we] live with" enables us first to "view the propriety and impropriety of [our] own passions"-and it is by imagining how those around us would view our conduct that we then "scrutinize [its] propriety" ourselves (TMS, 110, 112). Of course we substitute this self-scrutiny for the actual scrutiny of others to correct for the partiality and ignorance we find in much of that actual scrutiny. But in correcting for the passions and interests and misinformation of our friends and neighbors, we turn to an idealized version of our friends and neighbors who uses the same standards of moral judgment as they do. The impartial spectator is disinterested, well-informed and "candid" (TMS, 129), but is otherwise just like actual, partial spectators. It is built out of actual spectators; it is built, in particular, out of the basic reactive attitudes, the basic modes of moral judgment, that our actual friends and neighbors have. There is little in Smith's construction of the idealized spectator to correct for the surrounding society's standards of judgment; the idealized figure takes over those standards and corrects merely for their partial or illinformed use. If the moral standards, the basic moral sentiments, of a society are profoundly corrupt-if a feeling of contempt for Africans or hatred for Jews or homosexuals, say, has been taken for a moral feeling, 
and a society's judgments of these people's actions have been comprehensively skewed as a result-the impartial spectator within each individual will share in, rather than correcting for, that corruption. $^{12}$

Now it seems reasonable to suggest that the impartial spectator, as it corrects for misinformation and partiality in the application of its society's standards, can also accuse those standards themselves of being based on faulty information or of having arisen to serve the interests of some group or other within the society. ${ }^{13}$ Better information about Africans, or a better realization of how negative sentiments toward Africans served the interests of slave-owners, might have led people in America to abandon such ugly sentiments-especially if they also engaged in a serious attempt to imagine themselves in the place of the Africans affected by these sentiments. Smith may well have believed that tools of this sort would enable us to correct for moral corruption in the shared sentiments around us. I have myself argued elsewhere (Fleischacker 2003, Part IV, chapter 3) that Smith's writing of the Wealth of nations was in good part an attempt to change attitudes towards the poor, by providing better information about them, and by describing their circumstances in such a way as to encourage readers to project themselves, imaginatively, into the poor's shoes.

\footnotetext{
${ }^{12}$ This problem is exacerbated by the fact that the socially-shaped impartial spectator within us is not only our means of moral judgment; it is fundamental to the very self capable of issuing judgments of any sort. Smith never says anything about Hume's deconstruction of the self in A treatise of human nature, but his views in Book III of TMS depend heavily on the notion of a continuous, introspective self, that can look back on its own actions and take responsibility for them (see especially TMS, 111, $\mathrm{n}$ [3], 115-119, and 134-137). Society provides us with a "mirror" by which we see ourselves for the first time (TMS, 110). But that is to say that without this socially-constructed "mirror" we would not have become aware that we so much as had a self to scrutinize. Indeed, this puts the point too weakly. It is not just that, without the mirror provided by society, we would not be aware that we had a self; we would in fact not have a self. The metaphor of the mirror is misleading. I have a body before I see it in the mirror; the mirror gives me a way of becoming aware of my body, yet my body exists whether I am aware of it or not. But it is not at all clear that my self exists if I am not aware of it. On all standard accounts of selfhood, the self is by definition something that reflects upon itself, that is self-aware. However in that case Smith's self cannot so much as exist until it is awakened to such reflection by society. Society brings the self into existence, and at the same time provides the standards guiding its characteristic act of self-reflection. (One interesting consequence of this is that for Smith the self is primarily a moral rather than a cognitive being: our ability to introspect arises first and foremost in the moral arena. All the Lockean "reflex" senses are for Smith a product of moral practices first, and only later transferred to epistemic uses. This may be yet another anticipation of Kant: morality, not epistemology, gives us our best reasons to posit an ongoing self.)

${ }^{13}$ Stephen Darwall urged this objection on me.
} 
But it is unlikely that either better information, or the demonstration that certain attitudes are driven by partiality and interest, or even better imaginative projection, will in fact suffice to reform many corrupt attitudes. ${ }^{14}$ Prejudiced people are notoriously impervious to better information about the objects of their dislike: the information, even when accepted, gets filtered through their sentiments such that those who despise black people or Jews have commonly been able to come up with ingenious reasons why even facts that might seem to testify to these people's virtues are instead evidence of their vices. Nor will the claim that an attitude derives from interest or partiality necessarily make much headway. Any given individual can very often reasonably protest that she does not personally have any stake in discrimination against blacks or homosexuals - and it is personal stakes of this sort, "interests" and "inclinations" (TMS, 129), above all, that Smith means by "partiality". She may also, often, be able to argue with some plausibility that an impartial spectator procedure would endorse the attitude she holds. When we ask her to project herself into the feelings of the Jews or homosexuals hurt by the hostility directed at them, she may ask us, in response, to project ourselves into the feelings of those who find the practices of Jews or homosexuals offensive, or the feelings of Jews who themselves dislike Judaism and homosexuals who wish they were not gay. And if we try to reject this demand by saying that people who find Judaism or homosexuality offensive have improperly induced sentiments, that they are merely prejudiced, or, if themselves Jewish or gay, have just internalized the prejudices against them, they can retort that it is those who approve of Judaism or homosexuality, and the Jews or homosexuals who are proud of their practices, who have improperly formed feelings, who are allowing pride or selfish desire to block the repugnance they would, if truly impartial, feel about their evil way of life. And it will be difficult to break out of this circle of claim and

\footnotetext{
${ }^{14}$ And even if these appeals do succeed, in some or many cases, the claims of misinformation and partiality come too late to correct appropriately for the relativity of the impartial spectator. If Smith's spectator begins as a construction out of the actual sentiments of one's society, then its mode of procedure is essentially relative to the society in which it arises even if it manages sometimes to overcome that society's limitations. Any reaching beyond the society's limitations will be fortuitous, not built into the very nature of Smith's moral method. The method of a Kantian or a utilitarian is essentially absolutist and universalist in a way that Smith's method is not. Of course Smith's method has advantages, in theory and in practice, over that of both Kantians and utilitarians-it is closer to actual moral practice, more nuanced, and less conducive to arrogance and insensitivity-but those advantages are intimately bound up, I suggest, with the relativistic disadvantage I am here emphasizing.
} 
counter-claim using Smithian resources alone, since the impartial spectator, as Smith describes it, works best by relying on socially-shared sentiments as normative and then correcting a particular application of those sentiments for a gap in information, or dependence on interest, that all parties to the judgment in question could recognize as such. Smith's procedure generally corrects for very local failures of judgment, within a broader social context whose entrenched emotional commitments can be taken as normative. ${ }^{15}$

But a procedure that depends so heavily on its surrounding society is hardly in a good position to launch a radical critique of that society. If the basic attitudes of a society are globally corrupt or bigoted, the individuals within that society, on Smith's view, are unlikely even to be aware of that fact, let alone have a basis on which to change it. ${ }^{16}$

\section{SMITH'S UNIVERSALISM}

So Adam Smith stands convicted of cultural relativism. Or does he? I suggested in my first paper on Smith that the impartial spectator may be a source for Kant's categorical imperative, ${ }^{17}$ and Stephen Darwall has recently offered brilliant and beautiful elaborations of that possibility. ${ }^{18}$ But this suggests a very different view of Smith-one on which he would seem to be an opponent rather than an advocate of cultural relativism. We need now to draw out this Kantian side of Smith.

\footnotetext{
${ }^{15}$ It goes with this feature of Smith's theory that his focus is on self-correction and not on the reform of social standards of morality. The subtitle of TMS in its fourth edition was "An Essay towards an Analysis of the Principles by which Men naturally judge concerning the Conduct and Character, first of their Neighbours, and afterwards of themselves", and this captures nicely both the centrality of Book III in the work, which focuses entirely on the importance and difficulty of getting ourselves to live up to the moral standards we readily apply to others, and on the way that much of the rest of the book, especially insofar as it brings out "irregularities" in our modes of moral judgment, seems designed to get us to understand how we judge others primarily so that we can apply such judgment more properly-which means, above all, with less self-deceit-to ourselves. But this focus on getting ourselves to live up to moral standards makes it hard to pay much attention to the problem of reforming those standards themselves. Of course there is nothing logically infelicitous about developing a moral theory directed towards both self-judgment and reform of society. As a practical matter, however, the claim that society's standards of judgment are corrupt all too easily serves as yet another excuse for our self-deceiving attempts to exempt ourselves from all moral judgment (“Capitalism oppresses the poor, so I don't need to worry about ripping off my boss"). It is easier to bring the recalcitrant self into the process of self-judgment if the standards going into that process can be treated as fixed.

${ }^{16}$ Hence, perhaps, the acquiescence of Plato and Aristotle in infanticide, which Smith regards as fully understandable if not admirable (TMS, 210).

${ }^{17}$ See Fleischacker's (1991) "Philosophy and moral practice: Kant and Adam Smith".

${ }^{18}$ See Stephen Darwall's (1999) "Sympathetic liberalism”, and (2004) "Equal dignity".
} 
To begin with, Smith's express utterances display cosmopolitan aspirations as well as a respect for cultural differences. Although we are "commended by Nature" first to care for ourselves and our local societies, Smith says that we also have sentiments that go out to all human beings, indeed to all sentient beings: "[O]ur good-will is circumscribed by no boundary, but may embrace the immensity of the universe" (TMS, 235). The happiness of "any innocent and sensible being" is desirable to us, and we have an aversion to the misery of any such being. We have, in short, a capacity for "universal benevolence", and this benevolence, while limited in many people, and something that can "very seldom" be translated into "effectual good offices", seems to be a virtue that crowns moral development for Smith. The "wise and virtuous man is at all times willing", he says, to sacrifice his own and his local interests for the greater interest of the universe. Such a man sees the "great society of all sensible and intelligent beings" as embracing all the lesser societies to which he belongs.

But Smith's system provides us with no good explanation of how anyone can come to have these nobly cosmopolitan sentiments. As Jim Otteson has emphasized, Smith believes moral sentiments are tied very tightly to what Otteson calls a "familiarity principle" (Otteson 2002, 4) a principle according to which we care about people in proportion to how well we know them (see TMS, 139-140, 227-228). Our moral sentiments are also instilled in us by the people with whom we interact, and if the sentiments of our friends and neighbors are, as sentiments in most societies have been, infused with bitter or fearful reactions to those outside our group, then we will presumably be instilled with this tribalist animosity, rather than the cosmopolitan goodwill Smith praises.

So the express universalist utterances in TMS seem loosely attached to Smith's basic moral theory. More interesting are certain universalist implications to be found at the core of that theory. Some of the passages that I used above to show the cultural embeddedness of the impartial spectator can be understood instead to suggest exactly the opposite. For what does it mean that, in defence against the partial or ill-informed judgments of others, "we [...] learn to set up in our own minds a judge between ourselves and those we live with" (TMS, 129)? Yes, in part it means that we construct such a notional judge out of the mode of judging we have learned from "those we live with", but first and foremost it means that we attempt to step beyond our local context, to step beyond all partiality. It also means that we come to see ourselves 
as equal with every other human being. ${ }^{19}$ Indeed, the whole point of taking up the impartial spectator position may be that thereby, and only thereby, can we grasp the fundamental equality of human beings:

[T]o the selfish and original passions of human nature, the loss or of a very small interest of our own, appears to be of vastly more importance [...] than the greatest concern of another with whom we have no particular connexion. His interests, as long as they are surveyed from this station, can never be put into the balance with our own [...] Before we can make any proper comparison of those opposite interests, we must change our position. We must view them, neither from our own place nor yet from his, neither with our own eyes nor yet with his, but from the place and with the eyes of a third person, who has no particular connexion with either, and who judges with impartiality between us (TMS, 135). ${ }^{20}$

What we gain from overcoming self-love is that we can then grasp the true equality of humankind. The passage of TMS that describes the impartial "inhabitant of the breast" as "capable of astonishing the most presumptuous of our passions" goes on immediately to say that when our presumptuous passions are thus checked, we recognize "the real littleness of ourselves", the fact "that we are but one of the multitude, in no respect better than any other in it" (TMS, 137). Smith tells us over and over that we make our greatest moral mistakes when we try to assert superiority over other people. In the "race for wealth", everyone is allowed to "run as hard as he can, and strain every nerve and every muscle, in order to outstrip all his competitors", but if he should "justle, or throw down any of them", the spectators will not tolerate his behaviour: "This man is to them, in every respect, as good as he: they do

${ }^{19}$ Compare to Stephen Darwall's $(2004,132)$ reading of Smith on this point:

For Smith, when we judge an agent's motive, we do so from the agent's own perspective, viewing the practical situation as we imagine it to confront her in deliberation. And when we judge someone's feeling or reaction, we do so from her patient's perspective, viewing the situation as we imagine it to confront her as someone responding to it. Both judgments involve an implicit identification with, and thus respect for, the other as having an independent point of view.

[...]

For Smith, therefore, the implied framework of judgments of [...] propriety is a moral community among independent equal persons. Judgments of [propriety] involve an implicit inter-subjectivity, a projection into the standpoints of independent individuals that is disciplined by a standard of one among equals, as 'one of the multitude, in no respect better than any other in it (TMS, 137)'.

${ }^{20}$ See also TMS, 109-110, 228, and 129. 
not enter into that self-love by which he prefers himself so much to this other" (TMS, 83). Again:

What chiefly enrages us against the man who injures or insults us, is the little account which he seems to make of us, the unreasonable preference which he gives to himself above us, and that absurd self-love, by which he seems to imagine, that other people may be sacrificed at any time, to his conveniency or his humour (TMS, 96).

The point of the passage is to explain why even small acts of injustice seem to deserve punishment, and the argument is that even where the material harm done is slight, an act of injustice suggests that the victim is somehow less worthy than the agent, and thereby constitutes an important symbolic harm. The anger that boils out of the passage indeed captures wonderfully how we feel (one suspects: how Smith himself often felt) when another person seems to imagine that we "may be sacrificed at any time, to his conveniency or his humour", how bitterly we resent such a symbolic degradation below the equal worth that we think we share with all other human beings.

For Smith as for Kant, then, regarding all human beings as equal is essential to morality. ${ }^{21}$ It is especially important to the virtue of justice, but Smith makes clear that it is relevant also to other virtues: by telling

\footnotetext{
${ }^{21}$ One can bring Smith yet closer to Kant. "A moral being is an accountable being” says Smith (TMS, III.1-a passage left out of the 6th edition, see editors' note p. 111. Darwall emphasizes this passage in both of his essays: "Sympathetic liberalism" 1999, and "Equal dignity" 2004). Accountability or responsibility is for Smith, as for Kant, at the heart of his moral theory. Smith says, as had the Christian natural law tradition before him, that fundamentally we are accountable to God, but he also says that "in the order of time" we are accountable first and foremost to our fellow human beings. And he says that "accountable" means one "must give an account of [one's] actions to some other", and therefore "regulate" one's actions in accordance with that other's "good-liking". Aside from the reference to "liking" this is all extremely Kantian. "Account" is one of several philosophical descendants of Plato's word logos; "reason" is another. So to say one must give an "account" of one's actions is really to say that one must give a reason for them. To act morally is to be able to explain one's actions to another reasonable being. To act morally, then, is to act in a way of which reason can approve.

Smith does suggest at one point that taking up the impartial spectator position is equivalent to acting on reason. "It is reason, principle, conscience" he says, that informs us of "the real littleness of ourselves", and he goes to equate "reason, principle, [and] conscience", with "the inhabitant of the breast, the man within, the great judge and arbiter of our conduct" (TMS, 137). This reason, moreover, much like Kant's, rises above and can strike down all our emotions: it is capable of "astonishing the most presumptuous of our passions". This reason is also impartial, and it reveals, as noted, human equality. So it is very like Kant's reason, so much so that one may wonder whether Smith is really being entirely faithful to his moral sentimentalist commitments.
} 
us "that we are but one of the multitude" the impartial spectator shows us "the propriety of generosity" as well as "the deformity of injustice" (TMS, 137). If the achievement of impartial spectatorhood just is the achievement of a position from which all human beings appear as equal, then all virtues implicitly depend on a recognition of human equality.

Moreover, Smith makes clear that the equality we recognize from the impartial spectator position is not just an equality between ourselves and our immediate neighbours. The passage that tells us how important it is to learn that "we are but one of the multitude" begins by noting that "a man of humanity in Europe" would be little troubled if all of China were swallowed up by an earthquake, but would never actively sacrifice so many human lives, no matter how distant from his own society, for a paltry interest of his own (TMS, 137). ${ }^{22}$ "Reason, principle, conscience" informs us that each of these hundreds of millions of people is just as important as we ourselves are, that none of them can be sacrificed to our interests. But that is to say that none of the people in China, who for a Scot were as remote as anyone could possibly be, can be sacrificed to our interests, that each of them is equal to ourselves. ${ }^{23}$

Now can we use this recognition of human equality to extend Smithian ethics beyond local societies, and to criticize our own society when it is bigoted or otherwise morally corrupt? I am not sure. How are we supposed to tell whether our society is bigoted or not? Of course, there are many cases where it is clear that people in our society treat members of other cultures with no humane concern at all-as in the case of African slavery, or the treatment of indigenous people in the Americas, both of which Smith condemned indignantly (see TMS, 206-207; and WN, 448)-but in other cases, as when Christians have set out to convert supposedly barbaric natives or urged Jews to give up what they consider absurd practices, bigotry may hide itself under a sincere profession of benevolence. If the impartial spectator develops

\footnotetext{
${ }^{22}$ Note also the choice of language here: Smith says that this man would not sleep tonight if he was to lose his finger tomorrow, but would "snore with the most profound security" if "a hundred millions of his brethren" were destroyed; since the examples are meant to be equivalent ones, it is clear that we are supposed to think of the people in China as our "brethren".

${ }^{23}$ Perhaps it is no accident that the passage ends with language that will be echoed when Smith comes to talk of "universal benevolence". Propriety calls on us to "resign [...] the greatest interests of our own, for the yet greater interests of others", he says here; in TMS, VI. ii, he will tell us that the "wise and virtuous man" is always willing to sacrifice his private interest to the public interest of his neighbourhood and state, and that he should be willing to sacrifice "all those inferior interests" to "the interest of that great society of all sensible and intelligent beings".
} 
within us as Smith says it does, taking over the standards of our society even as it corrects the application of those standards for passion and partiality, then it is not obvious how we would ever be alerted to these kinds of hidden bigotry.

It is no more obvious how we would be alerted to other kinds of moral corruption, such as the sort that led, in Smith's view, to the acceptability of infanticide in the Greek world. Simply knowing that all human beings are equal will not do. The Greeks, after all, presumably believed that any child could be exposed. They were willing to extend their practice of infanticide equally to all human beings. Knowing that human beings are all equal is therefore not enough: we need also to know what sort of treatment befits these equal beings. And for that, Smith will presumably tell us to ask what sort of treatment we expect to be approved by the impartial spectator. But if the impartial spectator, again, operates on the fundamental standards upheld in the society around it, we can hardly expect it to judge those standards themselves as improper. So the impartial spectator is unlikely to tell us, since it is unlikely to be aware, that a kind of treatment prescribed for all human beings in our society, should be condemned.

\section{REFLECTIONS ON THIS TENSION}

Let me conclude by laying out four different ways one might handle the tension between the culturally relativist and the universalist strain in Smith's thought.

First, one could simply regard Smith's relativist leanings and his universalist ones as evidence of a deep contradiction at the foundations of his moral philosophy, and dismiss him and his philosophy on that basis. The indifference with which Smith's moral thought has often been met is probably due in good part to an impression that unresolved tensions plague his views at their root and that it is therefore unprofitable to think with Smith on ethics today in the way one might think with Aristotle or Hume or Kant or Mill. To which those of us who do want to think with Smith might respond that there is too much moral wisdom in Smith to give up on him so easily, but also that the tension in Smith between relativism and universalism is not just a matter of his having made some elementary mistake, that there are good reasons why Smith faces this tension and that it is one we continue to face ourselves. Unlike most philosophers, in his time or since, Smith is concerned in TMS to give a thorough account both of the fundamental 
principles that ought properly to guide moral judgment and of the way we in fact learn to make moral judgments from our parents, teachers, and peers. ${ }^{24}$ The more realistic one's account of moral development, however, the more one is faced with the fact that different societies lead people to differ, and differ irreconcilably, on the very standards for moral judgment. The more persuasive one's account of how people ought to judge, on the other hand, the more likely one will have to dismiss some societies as not properly having a practice of moral judgment at all. Hence the discomfiting fact, which no-one has yet figured out how to handle, that anthropologists for the past 75 years or so have widely taken for granted that any sensible person must be a moral relativist, while philosophers in the same period have been equally united in the belief that moral relativism is incoherent, upheld in any strong form only by idiots.

Which brings us to the second way we might handle the relativist/universalist tension in Smith: we might note that Smith, unlike most philosophers before him or since, recognizes the pull of both the anthropological and the philosophical approaches to morality, and applaud him for doing that, even if he did not figure out a satisfactory way to bring the two approaches together. The two approaches should be able to come together, after all: it is a problem for philosophers if what they say ought to guide most people's conduct in fact does not do so in most or all societies, and it is a problem for anthropologists if most or all of the practices for guiding conduct they study cannot be endorsed, on reflection, by any rational person. Smith offers a theory of morality more likely to win the respect of anthropologists than the theories of most other philosophers. It may be a consequence of that theory that he leaves himself without an effective way of criticizing deeply-held norms in one's society, or for showing why some deeplyheld norms, although taken to be moral ones, are not that. But we might say that this is the cost of trying to bring anthropological and philosophical approaches to morality together, commend Smith for the effort, and forgive him for failing to resolve the problem.

This second strategy too, however, leaves us with a fairly dismissive attitude toward Smith. "Nice try" does not amount to high praise for a philosophical project, and if we do think Smith raised a problem he

${ }^{24}$ Hume had done something similar, but his sociological account was sketchy, and depended heavily on his implausible "contagion" theory of how passions pass from one person to another (see A treatise of human nature, 317, 576; criticized by Smith at TMS, 11-12). 
could not solve, no matter how much of an excuse for that we may find in the motivations for his project, we will not be much inclined to think along with him as we do ethics ourselves. So we might want a third approach to the tension I have pointed to in Smith. One obvious one is to take up either Smith's relativism or his universalism and leave the other aspect of his theory behind. If we do the former, we are likely to see Smith, with Tom D. Campbell, ${ }^{25}$ as a sociologist of morals rather than a philosopher. If we do the latter, we can see Smith in the Kantian light that I and Darwall have urged. But both again risk relegating TMS to the past of moral philosophy rather than keeping it alive. For if Smith merely anticipates modern social scientific approaches to morality, then surely we want to turn from him to more recent sociological work, with better and more recent data, and a more sophisticated methodology. And if Smith merely anticipates Kant, then we might as well just turn to Kant himself.

Neither Darwall nor I has ever meant to say that Smith merely anticipates Kant, however. Those of us who see Kantian elements in Smith $^{26}$ usually find this connection exciting because we also find something in Smith that Kant lacks: a rich and realistic account of the moral emotions, above all, and of how they develop in society. We think-I, at any rate, do-that Smith could provide us with an account, which Kant himself does not give us, of how Kantian attitudes might arise in the course of moral education. ${ }^{27}$ But that is to say that we

\footnotetext{
${ }^{25}$ See Campbell's (1971) Adam Smith's science of morals. As evidence for his claim that Smith is giving us a scientific rather than a normative account of morals, Campbell endorses a fairly strong version of the relativistic reading of Smith $(1971,139-145)$.

${ }^{26}$ There are by now several: see for instance Knud Haakonssen's (1996) Natural law and moral philosophy, and Leonidas Montes's (2003) Adam Smith in context. In addition, several papers offered in Fricke and Schütt's (2005) volume-especially those by Georg Lohmann, Carola von Villiez, and Christel Fricke-connected Smith's methodology to insights either in Kant or in the modern Kantian, John Rawls.

${ }^{27}$ I suspect that the most promising direction for a solution to the problem I have stressed in this paper is to develop an account of how the development of the impartial spectator within us, in actual practice, implicitly brings with it richer opportunities for correcting the moral standards of our society than Smith himself allows. Moral education in every society, it may turn out, normally or even inevitably leads us to develop a judge within ourselves that is not just "candid", well-informed and disinterested, but that has at least an implicit understanding of and commitment to a truly dialectical interrogation of anything held up to us as a moral standard, and to a notion of the good, however thin and abstract, against the background of which such standards can be examined. What Charles Griswold, at the end of his great book on Smith (1999, 368-376), recommends as a supplement to Smith's moral thought-the revival of Socratic questioning about ethics-may then be found, implicitly, within Smith's thought itself. To determine whether this is so, however, a detailed account of
} 
are drawn by precisely the sociological aspects of Smith that raise the spectre of relativism. We cannot so easily render the tension in Smith harmless by taking the Kantian part we like and discarding the sociological remainder. ${ }^{28}$

I recommend, therefore, a fourth approach to the tension between relativism and universalism in Smith, and that is to use Smith to help find a resolution to that tension in our own moral thought. The split between the way philosophers view morality and the way anthropologists do is an important and disturbing one. There are both analytic and normative reasons for expecting the norms that ought to govern conduct to bear some fairly close relationship to the norms that actually govern conduct, for most people in most societies. A philosophical theory of morality that writes off most people, in most societies, as moral idiots is not only condescending but implausible. A social scientific view that makes moral norms out to be something no rational, reflective person could endorse is equally implausible-indeed, for similar reasons. So we ought to want to bring the philosopher's and the anthropologist's views of morality closer together and Smith may be a good source for helping us do that.

This fourth approach to Smith also has its dangers, however. I have proposed elsewhere that we can describe Smith as believing that a general sketch or outline of good conduct, and of the good human life, holds across all societies but that such general picture allows for details, and types of shading, to be filled in differently by different societies. ${ }^{29}$ That is one way of bringing the relativist and the universalist strands in Smith together, but I am not convinced it is adequate. It is quite vague, for one thing - what is to count as part of the general outline, and what as mere shading or detail? Notoriously, societies differ on the importance of certain broad features of human life: the emphasis on sexuality vis-à-vis spiritual devotion in modern, Western societies is

exactly how such Socratic tendencies might be implicit in actual moral education needs to be elaborated.

${ }^{28}$ Darwall may be less vulnerable to this charge than I am (in this, however, most of the others who connect Kant and Smith, mentioned above in note 26, are in the same boat with me). The second-person perspective Darwall finds in Smith but not in Kant, the recognition that claims of justice, at least, need to be made from a position that recognizes the other person as having an independent point-of-view, can be understood as an a priori, and certainly a universal, condition of doing ethics. Smith's own account assumes that the ability to recognize the other as occupying a separate perspective, and to try to project oneself into that perspective, is a precondition for all ethical systems.

${ }^{29}$ See Fleischacker 1999, 144-151; and 2003, Part II, chapter one. 
almost exactly the opposite of what it is in traditional Muslim, Jewish, Christian, or Hindu communities, for instance. Is this a matter of detail or a difference in general outline? I do not know how to settle that question. There may be a problem in principle about drawing such a distinction. On Smith's own view, general rules about conduct, and general notions of happiness, are drawn out of judgments in specific cases (TMS, 159-160). So the outline/detail distinction may not withstand much pressure. Moreover, the outline/detail distinction might reconcile Smith's universalism with his cultural pluralism, but it does little to help overcome his implicit relativism. The problem that gives rise to the ambivalent attraction many of us have to Smith is that the impartial spectator is both underwritten by a basic respect for all other human beings and shaped by the attitudes of a specific, local society. No amount of talk about details and shading will help overcome the relativity of the spectator to the attitudes that prevail in the society around it. And that relativity can undermine even Smith's pluralism: most of the people in many societies vigorously condemn cultural pluralism, vigorously uphold their own way of living as the only right way, and in those societies the impartial spectator will presumably take over that attitude as normative.

So Smith is unlikely to offer us any straightforward meta-ethical reconciliation between relativism and absolutism, and his promising hints about how, in ethics proper, to bring together pluralism and universalism, are undermined, to some degree, by his meta-ethical dilemma. But the problems he faces in these regards are our problems too, and thinking with Smith may help nudge us toward a solution to them, even if that solution is not explicitly to be found in Smith's own work.

\section{REFERENCES}

Boas, Franz. 1932. Anthropology and modern life. New York: W. W. Norton \& Co., Inc.

Campbell, Tom D. 1971. Adam Smith's science of morals. London: George Allen and Unwin, Ltd.

Darwall, Stephen. 1999. Sympathetic liberalism: recent work on Adam Smith. Philosophy and Public Affairs, 28 (2): 139-164.

Darwall, Stephen. 2004. Equal dignity in Adam Smith. The Adam Smith Review, 1: 129-134.

Fleischacker, Samuel. 1991. Philosophy in moral practice: Kant and Adam Smith. KantStudien, 82 (3): 249-269.

Fleischacker, Samuel. 1994. The ethics of culture. Ithaca: Cornell University Press. 
Fleischacker, Samuel. 1999. A third concept of liberty: judgment and freedom in Kant and Adam Smith. Princeton: Princeton University Press.

Fleischacker, Samuel. 2003. On Adam Smith's Wealth of nations: a philosophical companion. Princeton: Princeton University Press.

Fricke, Christel, and Hans-Peter Schütt (eds.). 2005. Adam Smith als moralphilosoph. Berlin: Walter de Gruyter.

Geertz, Clifford. 1983. Common sense as a cultural system. In Local knowledge. New York: Basic Books, Inc., 73-93.

Gibbard, Allan. 1990. Wise feelings, apt choices. Cambridge (MA): Harvard University Press.

Griswold, Charles L., Jr. 1999. Adam Smith and the virtues of enlightenment. Cambridge (UK): Cambridge University Press.

Haakonssen, Knud. 1996. Natural law and moral philosophy: from Grotius to the Scottish Enlightenment. Cambridge (UK): Cambridge University Press.

Hume, David. 1994 [1772-1777]. Political essays, ed. Knud Haakonssen. Cambridge (UK): Cambridge University Press.

Hume, David. 1992 [1739-1740]. A treatise of human nature, eds. P. H. Nidditch, and L. A. Selby-Bigge. Oxford: Oxford University Press.

Hume, David. 1989 [1777]. An enquiry concerning the principles of morals. In Enquiries concerning human understanding and concerning the principles of morals, eds. P. H. Nidditch, and L. A. Selby-Bigge. Oxford: Oxford University Press.

Kroeber, Alfred L. 1948. Anthropology. New York: Harcourt, Brace and Co.

MacIntyre, Alasdair. 1984. After virtue: a study in moral theory. Notre Dame: University of Notre Dame Press.

Montes, Leonidas. 2003. Adam Smith in context: a critical reassessment of some central components of his thought. New York: Palgrave Macmillan.

Otteson, James R. 2002. Adam Smith's marketplace of life. Cambridge (UK): Cambridge University Press.

Smith, Adam. 1982 [1759-1790]. The theory of moral sentiments (TMS), eds. D. D. Raphael, and A. L. Macfie. Indianapolis: Liberty Fund.

Smith, Adam. 1976 [1776-1789]. An inquiry into the nature and causes of the wealth of nations (WN), eds. R. H. Campbell, A. S. Skinner, and W. B. Todd. Indianapolis: Liberty Fund.

Samuel Fleischacker is a professor of philosophy at the University of Illinois, Chicago. His particular research interests are the moral status of culture, the nature and history of liberalism, and the relationship between moral and other values (aesthetic values, religious values, political values). His publications include $A$ third concept of liberty: judgment and freedom in Kant and Adam Smith (Princeton, 1999); On Adam Smith's Wealth of nations: a philosophical companion (Princeton, 2003); A short history of distributive justice (Harvard, 2004); and Divine teaching and the way of the world (Oxford, 2011).

Contact e-mail: <fleischert@sbcglobal.net> 